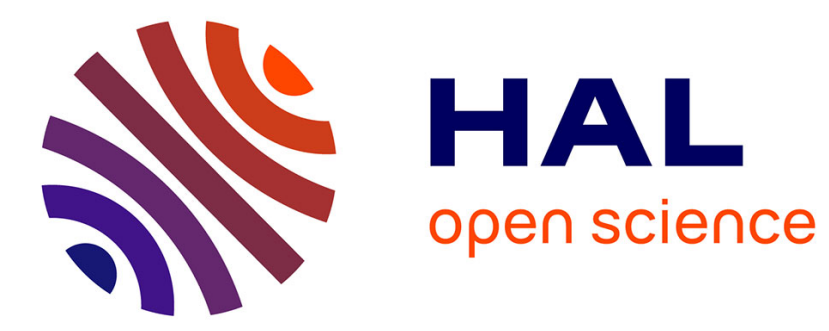

\title{
Numerical-experimental confrontation in the simulation of tool/abradable material interaction
}

\author{
Alain Batailly, Marion Cuny, Mathias Legrand, Sylvain Philippon
}

\section{To cite this version:}

Alain Batailly, Marion Cuny, Mathias Legrand, Sylvain Philippon. Numerical-experimental confrontation in the simulation of tool/abradable material interaction. Journal of Engineering for Gas Turbines and Power, 2013, 135 (6), pp.062102. 10.1115/1.4023262 . hal-00826981

\section{HAL Id: hal-00826981 \\ https://hal.science/hal-00826981}

Submitted on 10 Apr 2014

HAL is a multi-disciplinary open access archive for the deposit and dissemination of scientific research documents, whether they are published or not. The documents may come from teaching and research institutions in France or abroad, or from public or private research centers.
L'archive ouverte pluridisciplinaire HAL, est destinée au dépôt et à la diffusion de documents scientifiques de niveau recherche, publiés ou non, émanant des établissements d'enseignement et de recherche français ou étrangers, des laboratoires publics ou privés.

\section{(c)(1)}

Distributed under a Creative Commons Attribution| 4.0 International License 


\title{
Confrontation entre résultats expérimentaux et numériques pour la simulation de l'interaction outil/abradable
}

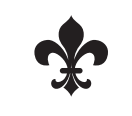

\begin{abstract}
Alain Batailly
Laboratoire de Dynamique des Structures et Vibrations, Département de Génie Mécanique, Université McGill, 817 rue Sherbrooke Ouest, Montréal, Québec H3A 0C3
\end{abstract}

\section{Marion Cuny}

Laboratoire de mécanique, Biomécanique, Polymères, Structures (LaBPS), Ecole Nationale d'Ingénieurs de Metz (E.N.I.M.), 1 route d'Ars Laquenexy, 57078 Metz, France

\section{Mathias Legrand}

Laboratoire de Dynamique des Structures et Vibrations, Département de Génie Mécanique, Université McGill, 817 rue Sherbrooke Ouest, Montréal, Québec H3A 0C3

\section{Sylvain Philippon}

Laboratoire de mécanique, Biomécanique, Polymères, Structures (LaBPS), Ecole Nationale d'Ingénieurs de Metz (E.N.I.M.), 1 route d'Ars Laquenexy, 57078 Metz, France

\section{Résumé}

Le dépôt d'un revêtement abradable sur le carter est reconnu depuis plusieurs années comme une solution robuste permettant à la fois un ajustement des jeux de fonctionnement et une limitation des dégâts causés par des contacts entre les sommets d'aube et le carter environnant. En particulier, la modélisation de l'enlèvement de matière se produisant lors de contacts est d'une importance grandissante d'un point de vue industriel. À partir d'une stratégie numérique présentée dans de précédentes publications par les mêmes auteurs, cette étude se focalise sur la description du comportement mécanique des revêtements abradables utilisés au sein des turbomachines dans le contexte d'interactions à hautes vitesses avec un outil rigide. La loi plastique utilisée pour la représentation macroscopique du matériau abradable est tout d'abord enrichie afin de prendre en compte une dépendance au taux de déformation du matériau. Puis, une étude de sensibilité est conduite par rapport à certains paramètres lesquels sont ensuite calibrés pour obtenir une bonne approximation de résultats expérimentaux. Finalement, l'influence de la dépendance au taux de déformation est évaluée dans le contexte de simulations de contacts aubes/carter au sein de turbomachines. 


\title{
Numerical-experimental confrontation in the simulation of tool/abradable material interaction
}

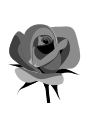

\begin{abstract}
In turbomachinery, depositing abradable coatings along the circonference of casings is recognized as a robust solution which combines the adjustment of operating clearances with the reduction of non-repairable damages potentially affecting the rotating blades. Accordingly, the modeling of the removal process experienced by these materials is of growing industrial importance. Based on a numerical strategy detailed in a previous publication by the authors, the present study aims at describing the mechanical behavior of abradable coatings used within turbomachines in the context of translational high-speed interactions with a rigid tool. The developed plastic constitutive law macroscopically capturing the abradable material removal is first enriched to account for its strain rate dependence. Then, a sensitivity analysis with respect to a few parameters of interest is conducted and calibration of the numerical investigation with existing experimental data validates the proposed approach. Finally, the strain-rate dependence of the viscoplastic law implemented within a full numerical three-dimensional rotor/stator interaction is addressed. Results reveal that viscoplastic terms have minor effects in turbomachinery interactions.
\end{abstract}

\section{Nomenclature}

$\alpha \quad$ internal hardening variable

- differentiation with respect to time

$\ell \quad$ width of the blade

$\eta \quad$ viscoplastic coefficient

$\gamma \quad$ flow rule

$\mathbf{F}_{\mathrm{i}} \quad$ contact force for each contact node

$\mathbf{f}_{\mathrm{i}} \quad$ contact force for each abradable element

$\sigma \quad$ axial stress within a bar element

$\sigma_{\mathrm{Y}} \quad$ yield limit of the bar element

$\varepsilon \quad$ axial strain within a bar element

$\varepsilon^{\mathrm{p}} \quad$ axial plastic strain within a bar element

$\varepsilon^{\mathrm{vp}} \quad$ axial viscoplastic strain within a bar element

$c_{i} \quad$ contact node number

E Young's modulus

$f(\sigma, \alpha) \quad$ plasticity criterion

$f_{\Omega} \quad$ rotational frequency

$h \quad$ time step

$\mathrm{K} \quad$ plastic modulus

$p \quad$ penetration of the tool within the abradable material

$r \quad$ sharpness of the tool 


$\begin{array}{ll}u & \text { displacement } \\ \mathrm{V} & \text { linear speed of the projectile } \\ \mathrm{F}_{\mathrm{i}} & \text { contact force in the } \mathbf{z} \text { direction for each contact node }\end{array}$

\section{Introduction}

In turbomachinery, mitigating unavoidable parasitic leakage flows between successive compressor stages is crucial for enhanced energy efficiency. To this end, designers tend to reduce the clearance between rotating bladed-disk assemblies and their respective surrounding stationary casings. As a result, structural mechanical interactions through direct unilateral contact occurrences are expected to arise. Because of their potentially destructive consequences such as modal interaction [1] or rubbing [2], comprehension and control of these interactions are crucial and involve both numericists $[3,4,5]$ and experimenters [1, 2].

Among investigated design strategies to avoid unilateral contact between blades and casings, depositing an abradable coating on casings is widely recognized as a robust solution combining the automatic adjustment of operating clearances with the reduction of potential nonrepairable structural damages [6]. This liner acts as a sacrificial material to be cut away by the blades so that in-use clearance always remains at a minimum. This material should be sufficiently soft to avoid significant blade damage as well as adequately resilient to stand very high temperatures and high-speed gas flows carrying inherent solid particles [7]. Only a few studies may be found in the literature regarding the identification of mechanical properties of abradable materials $[7,8,9]$. A majority of these works deals with static or low speed standard scratch tests since high speed experimental set-ups are both very costful and arduous to implement.

Recent developments $[10,11]$ are concerned with full three-dimensional contact numerical investigations on one aircraft-engine compressor stage where abradable coating removal is modeled as a virtual material undergoing a mono-dimensional plastic constitutive law which features three parameters detailed in the sequel. Corresponding results reveal consistency with physical considerations such as structural well-localized vibratory resonance of the blades. Ideally, the calibration of these parameters should be conducted in the framework of full size turbomachines but cannot be achieved at a reasonable cost.

In this context, the present study aims at calibrating the three numerical parameters of the existing plastic constitutive law by exploring idealized interaction configurations between a rigid tool and a targeted abradable coating. The experiments of interest and respective data are detailed in [12]. These tests were designed to launch a cubic patch of M601 abradable material against a quasi rigid tool made of steel $42 \mathrm{CrMo} 4$ and pictured in Fig. 1(a). The M601 abradable material has been widely studied and useful information on its properties is referenced in the literature [6, 7]. Most notably, its high abradability and poor erosion resistance have been observed experimentally [13].

The first section of this paper introduces the test-rig as well as the main assumptions of the corresponding modeling. Then, the mono-dimensional plastic constitutive law is briefly explained together with its inherent limitations: an extension toward a more realistic viscoplastic constitutive law with strain-rate dependence is proposed. Results are then discussed for a wide range of interaction speeds. The last section describes blade-tip/abradable coating interaction numerical simulations where the influence of the new viscoplastic constitutive law is assessed through comparisons with previous results. 


\section{Vocabulary}

Two types of interaction are analyzed in this study. While the vocabulary may be similar in both situations, the respective terminology is clarified here with no ambiguity:

1. The tool/abradable material interaction refers to an experiment collectively involving a motionless cutting tool and a projectile which supports an abradable patch as described in section 3.1. The portion of the tool in contact with the projectile is referred to as the blade-edge.

2. The blade-tip/abradable coating interaction refers to an interaction occurrence within turbomachines where abradable coating is added as a sacrificial layer. A brief explanation is supplied in section 5.4. The blade is then visualized as an elementary cyclic sector of a full bladed-disk assembly. The part of the blade in contact with the abradable coating is referred to as the blade-tip.

\section{Tool/ abradable interaction}

\subsection{Description of the experiments}

The blade-tip/abradable coating contact occurrence is studied through an experimental device designed to measure the contact forces arising during the interaction [12]. The device comprises a pneumatic gun depicted in Fig. 1(a) which exploits the sudden expansion of compressed nitrogen to launch a projectile at velocities up to $500 \mathrm{~m} / \mathrm{s}$. This projectile supports the abradable material sample. It is guided along a launch tube and interacts with a tool representing the blade-edge pictured in Fig. 1(b). The influence of several parameters such as (1) the interaction projectile speed, (2) the incursion depth, (3) the blade-edge geometry on the cutting force is investigated.

The interaction speed is adjusted through the initial gas pressure in the pneumatic gun and measured by three laser diodes located at the launch tube exit point. The incursion depth is setup by the position of the tool. For each test, its mean value and deviation during the interaction process are measured by comparing the sample height before and after the experiment.

The cutting forces generated during the interaction are measured by a piezoelectric sensor. A signal post-processing method based on modal analysis principles is implemented in order to virtually increase the bandwidth of the data acquisition system and subsequently precisely measure the axial cutting force [12]. Unavoidable inertial phenomena as well as the tool and sensor dynamics do not interfere with the measured force.

The purpose of these experiments is to characterize the material behavior of the abradable coating M601 through the measurement of the axial cutting reaction, regardless of the tool dynamics, to subsequently feed numerical models. Many parameters have an influence on the plastic constitutive law such as the incursion depth, the shape of the blade-edge of the tool, the tool material, etc. As a first approach, only the first two parameters were investigated in [12]. The tool shape and material were kept identical during the experiments as the blade-edge was regularly sharpened to maintain a $25 \mu \mathrm{m}$ radius. For different practical reasons detailed in [12], the tool is made of steel $42 \mathrm{CrMo} 4$ which differs from the usual material of a compressor blade: this is in agreement with the hypothesis that the tool material has a negligible effect on the observed phenomena as opposed to the velocity and incursion depth of the projectile. 


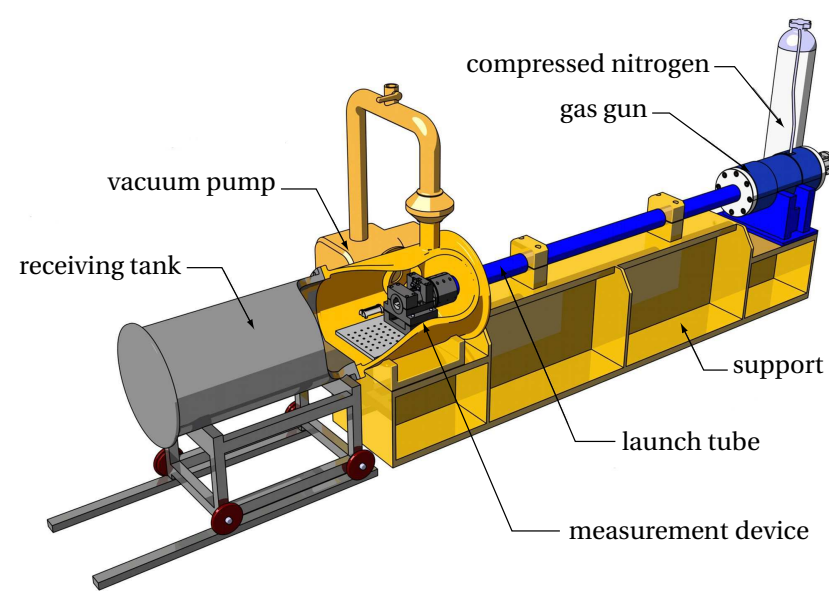

(a) Global view

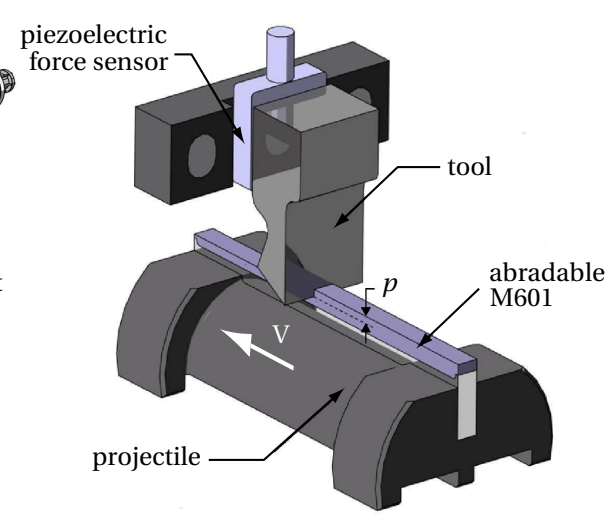

(b) Zoom on tool and projectile

Figure 1: Experimental test bench

Orthogonal cutting experiments on abradable material M601 were performed for a range of interaction velocities varying from $60 \mathrm{~m} / \mathrm{s}$ to $270 \mathrm{~m} / \mathrm{s}$. The theoretical incursion depth was set to $p=0.2 \mathrm{~mm}$ for all experiments. However the post-experiment analysis of the samples shows that the mean incursion depth varied from $0.13 \mathrm{~mm}$ to $0.35 \mathrm{~mm}$. This significant variation may be explained, among other, by the errors committed during the sample preparation and the positioning of the tool, by the potentially disturbing projectile dynamics as well as the existence of spurious gaps between the projectile and the guiding parts.

\subsection{Proposed modeling and numerical strategy}

The geometry of the tool presented in this section does not exactly match the one in [12] since it is understood that the key contribution to the interaction phenomenon stems from the bladeedge only [14].

The tool is discretized with finite element linear tetrahedrons. The mesh depicted in Fig. 2 is the result of a compromise between the number of nodes and the accuracy of the approximation of the 25 first eigenfrequencies. A convergence analysis based on the MAC criterion shows that a mesh composed of 1,835 nodes and 8,913 tetrahedron elements should reliably capture low frequency responses.

The tool is rigidly fixed to the test bench through a hole made in its back side as depicted in Fig. 2. All the nodes of the mesh on the surface of this hole (pictured in blue) are clamped. Fifteen nodes are symmetrically positioned on the edge of the tool blade. The width of the projectile is one third of the blade width and only the five middle nodes - namely $\left(c_{i}\right)_{i=1, \ldots, 5}$ pictured in red - are used to test the contact conditions.

A reduced-order model of the tool is built in order to substancially decrease the computational effort. The Craig-Bampton [15] component mode synthesis method is preferred: its compatibility with the implemented contact algorithm and its advantages over other component mode synthesis techniques were highlighted in $[5,16]$. The final reduced-order model contains 75 degrees-of-freedom and allows for a very accurate approximation of the first 25 eigenfrequencies of the full finite element model.

A simplified representation of the contact configuration described in section 3.1 is pictured 

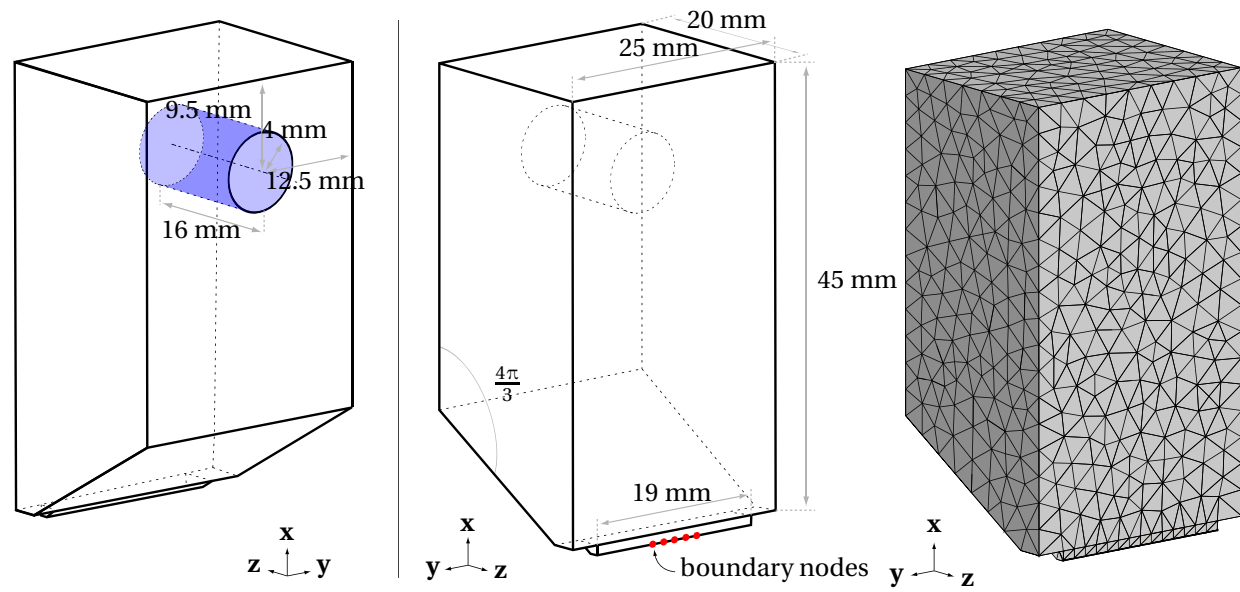

Figure 2: Tool mesh and prescribed boundary conditions

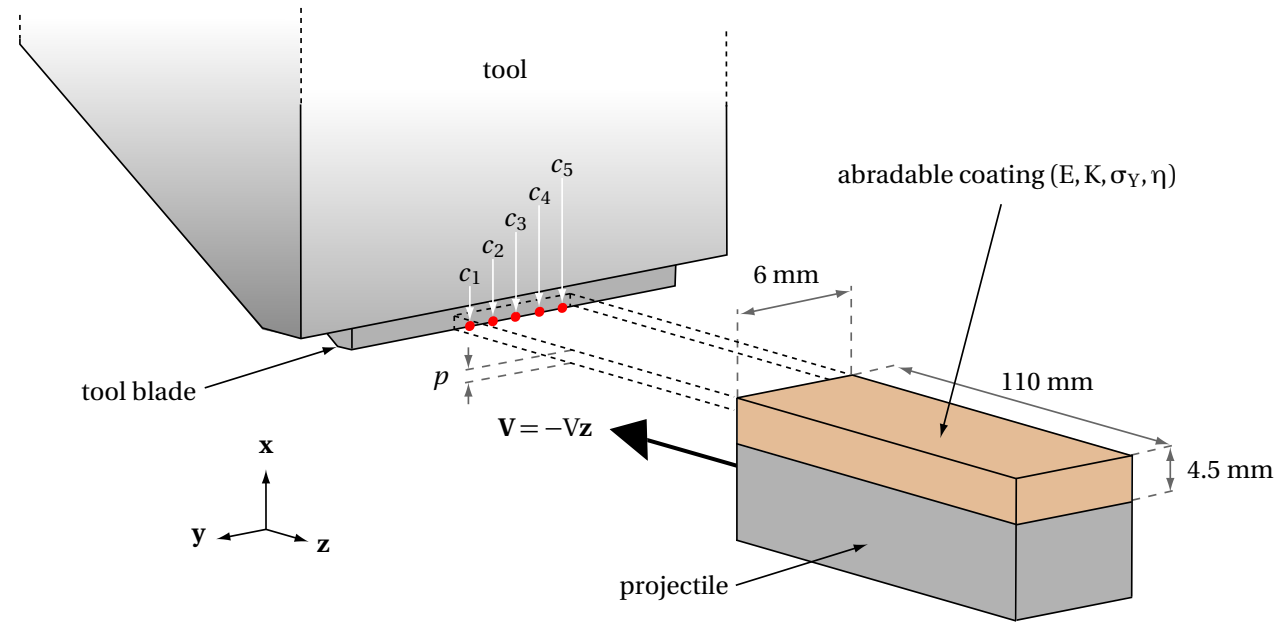

Figure 3: Schematics of the numerical simulation

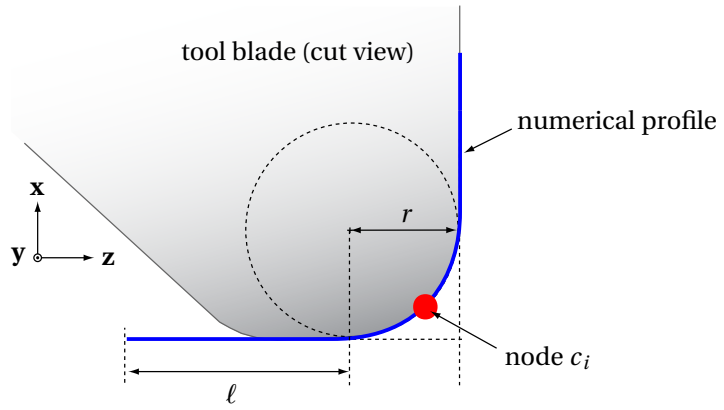

Figure 4: Tool blade zoom: cut view in the $\left(c_{i}, \mathbf{z}, \mathbf{x}\right)$ plane

in Fig. 3. In order to account for the width of the blade-edge of the tool in the $\mathbf{z}$ direction, a numerical profile is conveniently used for each contact node as displayed in Fig. 4. This profile allows for an accurate representation of the blade-edge of the tool, parametrized by its width $\ell$ and sharpness $r$. The removal of the abradable liner is reflected by the plastic distortion 
of a properly designed array of two-noded rod elements - called abradable element in the following - depicted in Fig. 5. The bar length stores the initial abradable thickness. Also, the reference frame is attached to the projectile so that the tool is virtually moving. During each

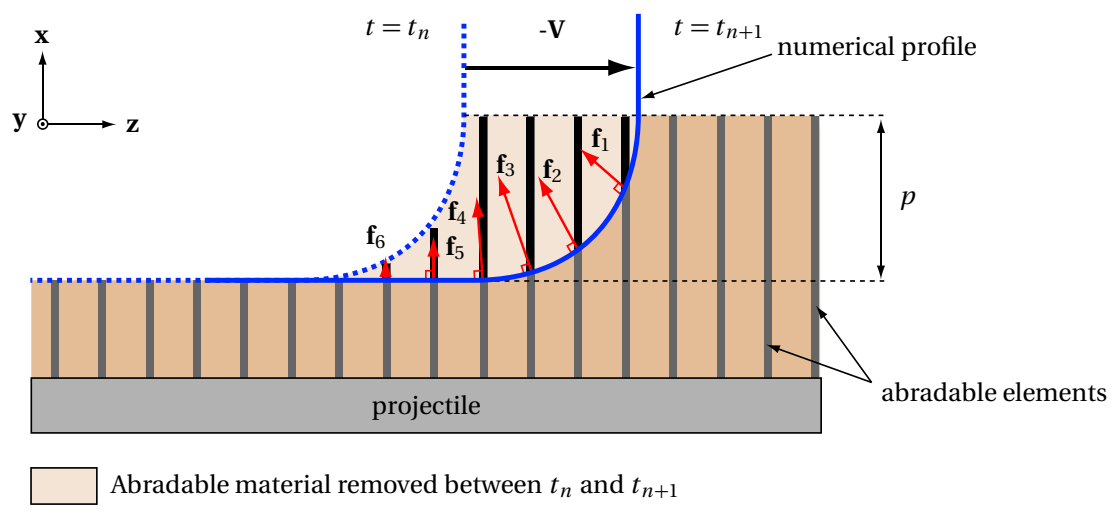

Figure 5: Numerical profile/abradable material interface

time-marching iteration, the contact forces computation is conducted through the detection of penetrations between the abradable elements and the blade-edge profile as detailed in [10]. The abradable elements can shrink in the $\mathbf{x}$ direction only but the resulting contact force $\mathbf{f}_{k}$ exerted on the tool is colinear to the numerical profile normal vector at the intersection of the abradable element with this profile as depicted in Fig. 5.

The contact force on each contact node $c_{i},(i=1, \ldots, 5)$ is given by:

$$
\mathbf{F}_{i}=\sum_{k} \mathbf{f}_{k}
$$

where $k=1, \ldots, 6$ refers to one of the abradable element in which the tool penetrates from a time step to another as pictured in Fig. 5. The contact force $\mathbf{F}_{i}$ applied on each contact node $c_{i}$ has both $\mathbf{x}$ and $\mathbf{z}$ components that are accounted for in the simulation. However, in order to remain consistent with the experiments of [12], results given in this paper only feature the $\mathbf{z}$ component of the contact force. This component is named $\mathrm{F}_{i}$ and is defined as:

$$
\mathrm{F}_{i}=\sum_{i} \mathbf{F}_{i} \cdot \mathbf{z}
$$

It is important to notice that this modeling of the tool blade implies that the cutting force in the $\mathbf{z}$ direction will reduce to zero if the tool is infinitely sharp, ie $r \simeq 0$. As counter-intuitive at this may seem, this is supported by experimental results given in [14] for similar experiments.

\subsection{Time and space convergence}

The implemented explicit time-marching integration procedure relies on the central finite difference method for which the time step is $h=10^{-8} \mathrm{~s}[4,10]$. Asymptotic time convergence of the contact nodes displacements is found with perfect superimposition for three different time steps in Fig. 6(a) and 6(b). Space convergence is achieved for 50,000 abradable elements along the length of the projectile ${ }^{1}$.

\footnotetext{
${ }^{1} 50,000$ abradable elements are used in front of each contact nodes so that the total number of abradable elements is 250,000 .
} 


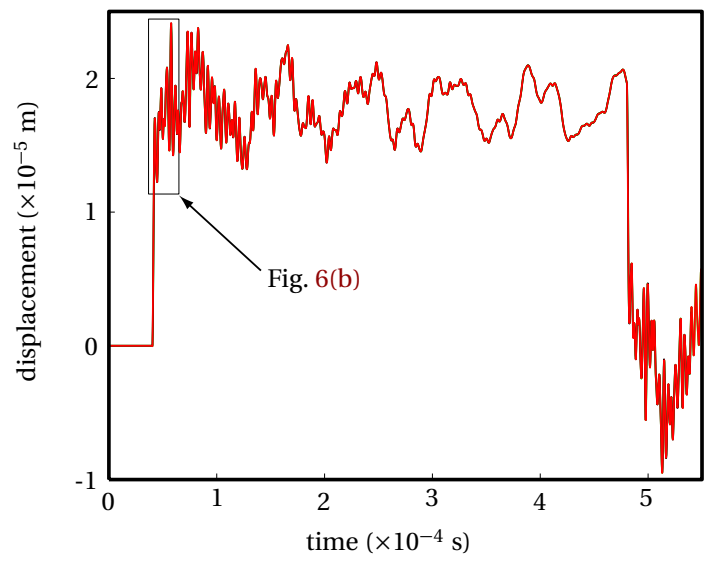

(a) Full simulation

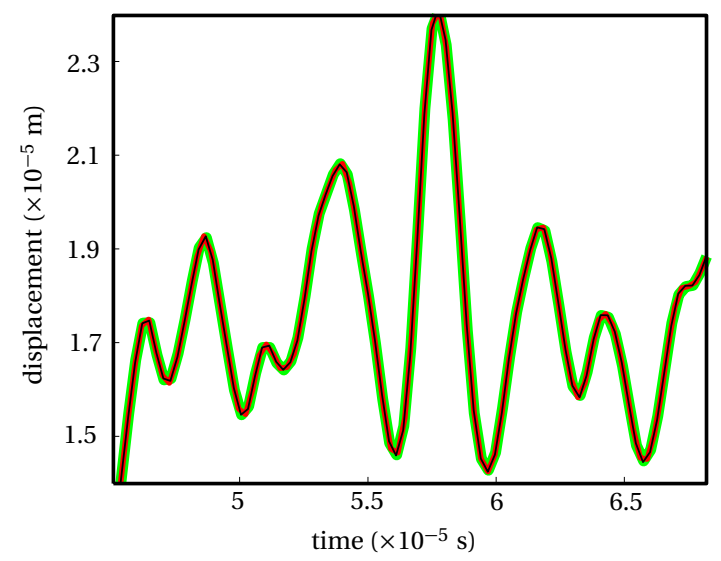

(b) Zoom

Figure 6: Displacement of node $c_{3}$ in the $\mathbf{x}$ direction for $h=10^{-8} \mathrm{~s}(-), h=5 \cdot 10^{-9} \mathrm{~s}(-)$ and $h=10^{-9} \mathrm{~s}(-) ;\|\mathbf{V}\|=200 \mathrm{~m} / \mathrm{s}$ and $p=0.5 \mathrm{~mm}$

\section{Extension of plastic constitutive law}

The plastic constitutive law introduced in [10] is one-dimensional, strain-rate independent with isotropic hardening. For full three-dimensional simulations ${ }^{2}$, this law acts as a satisfying compromise between accuracy and reasonable computational costs. However, preliminary numerical predictions with the rigid tool benchmark show that the resulting contact force is independent on the projectile's translational velocity which is not consistent with experimental data [12]. Indeed, the very high linear speed and the level of penetration within the abradable material make the strain rate exceeds $\dot{\varepsilon}=1000 \mathrm{~s}^{-1}$ which is the usual threshold from which strain rate should not be ignored in plastic constitutive laws $[17,18]$. Accordingly, an extension to one-dimensional classical viscoplasticity is proposed.

\subsection{From plasticity to viscoplasticity}

The plastic constitutive law detailed in $[19,10]$ shall be summarized as follows:

$$
\begin{aligned}
& \sigma=\mathrm{E}\left(\varepsilon-\varepsilon^{\mathrm{p}}\right) \\
& \dot{\varepsilon}^{\mathrm{p}}=\gamma \cdot \operatorname{sign}(\sigma) \\
& \dot{\alpha}=\gamma \\
& f(\sigma, \alpha)=\|\sigma\|-\left(\sigma_{Y}+\mathrm{K} \cdot \alpha\right) \leq 0 \\
& \gamma \geq 0, \quad f(\sigma, \alpha) \leq 0, \quad \gamma \cdot f(\sigma, \alpha)=0 \\
& \gamma \cdot \dot{f}(\sigma, \alpha)=0 \quad \text { if } f(\sigma, \alpha)=0
\end{aligned}
$$

where superscript ${ }^{\mathrm{p}}$ stands for plastic. The flow rule is defined by $\gamma=\dot{\varepsilon}^{\mathrm{p}}$ and $\alpha$ is commonly called internal hardening variable such that $\dot{\alpha}=\gamma$. By definition of a strain-rate independent plastic constitutive law, the criterion function $f$ must be negative at all times, ie $f \leq 0$. This

\footnotetext{
${ }^{2}$ Full 3D simulations involve 3D finite element models of the structures combined with the one-dimensional plastic constitutive law.
} 
mathematically defines the admissible domain pictured in Fig. 7(a) which the point $(\varepsilon, \sigma)$ belongs to ${ }^{3}$. Furthermore, yield strength $\sigma_{Y}$ of metals such as aluminium - which is the main

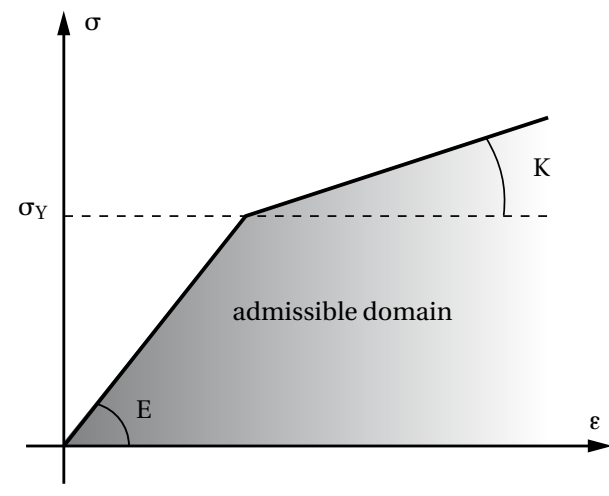

(a) Plasticity

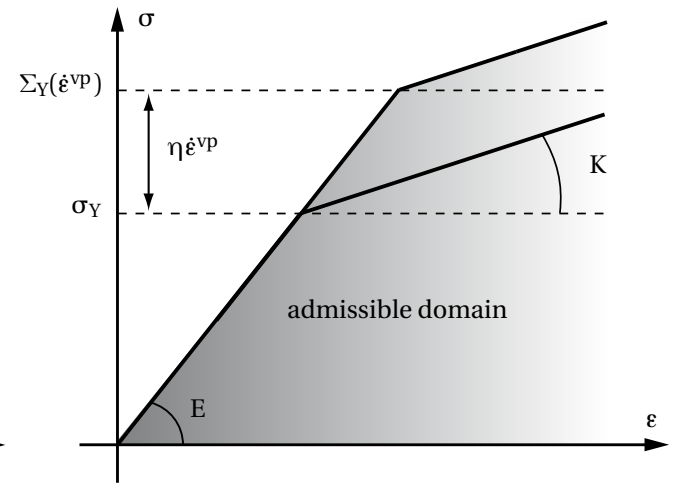

(b) Viscoplasticity

Figure 7: Investigated constitutive laws

component of abradable material M601 [7] —, is strongly affected by the strain-rate, as experiments [20,17] report. As a consequence, the criterion function $f$ in Eq. (3) may now be positive. The new assumption takes the form:

$$
f \geq 0 \Rightarrow f=\sigma_{\mathrm{ex}}=\eta \cdot \dot{\varepsilon}^{\mathrm{vp}}
$$

where $\sigma_{\text {ex }}$ is the extra stress and $\eta$ is a viscous coefficient expressed in Pa s. A new criterion function $g$ is defined as:

$$
g(\sigma, \alpha)=f(\sigma, \alpha)+\eta \cdot \dot{\varepsilon}^{\mathrm{vp}} \quad \text { where } \quad g \leq 0
$$

which yields:

$$
g(\sigma, \alpha)=\|\sigma\|-\left(\sigma_{Y}+\eta \cdot \dot{\varepsilon}^{\mathrm{vp}}+\mathrm{K} \cdot \alpha\right)
$$

and may be recast in:

$$
g(\sigma, \alpha)=\|\sigma\|-\left(\Sigma_{Y}+K \cdot \alpha\right)
$$

The criterion function satifies $g \leq 0$ thus defining a scalable admissible domain illustrated in Fig. 7(b) and similar to the strain-rate independent one with:

$$
\Sigma_{\mathrm{Y}}\left(\dot{\varepsilon}^{\mathrm{vp}}\right)=\sigma_{\mathrm{Y}}+\eta \cdot \dot{\varepsilon}^{\mathrm{vp}}
$$

which stands as the viscoplastic strain-rate dependent yield limit.

\subsection{Solution method}

By convention, an axial stress $\sigma$ acting within a bar element is positive which simplifies, to some extend, the equations.

\footnotetext{
${ }^{3} \mathrm{~A}$ symmetric domain with respect to the abscissa axis shall also be assumed depending on the type of sollicitation on the plastic element.
} 
It is assumed that the quantities $\sigma_{\mathrm{n}}, \varepsilon_{\mathrm{n}}, \varepsilon_{\mathrm{n}}^{\mathrm{vp}}, \alpha_{\mathrm{n}}$ during the $n^{\text {th }}$ time step are known. The next state of the system is predicted by assuming a purely elastic step:

$$
\begin{aligned}
& \sigma_{\mathrm{n}+1}^{\mathrm{g}}=\mathrm{E}\left(\varepsilon_{\mathrm{n}+1}-\varepsilon_{\mathrm{n}}^{\mathrm{vp}}\right) \\
& \varepsilon_{\mathrm{n}+1}^{\mathrm{vp}, \mathrm{g}}=\varepsilon_{\mathrm{n}}^{\mathrm{vp}} \\
& \alpha_{\mathrm{n}+1}^{\mathrm{g}}=\alpha_{\mathrm{n}} \\
& f_{\mathrm{n}+1}^{\mathrm{g}}=\left\|\sigma_{\mathrm{n}+1}^{\mathrm{g}}\right\|-\left(\sigma_{\mathrm{Y}}+K \alpha_{\mathrm{n}}\right)
\end{aligned}
$$

where superscript $\mathrm{g}$ stands for guessed and refers to the predicted values. From the predicted states, two cases are to be tested:

1. $f_{\mathrm{n}+1}^{\mathrm{g}} \leq 0$, then the step is indeed purely elastic and the guessed state is admissible:

$$
\begin{aligned}
& \sigma_{\mathrm{n}+1}=\sigma_{\mathrm{n}+1}^{\mathrm{g}} \\
& \varepsilon_{\mathrm{n}+1}^{\mathrm{vp}}=\varepsilon_{\mathrm{n}}^{\mathrm{vp}} \\
& \alpha_{\mathrm{n}+1}=\alpha_{\mathrm{n}}
\end{aligned}
$$

2. $f_{\mathrm{n}+1}^{\mathrm{g}}>0$, then $f_{\mathrm{n}+1}=\eta \dot{\varepsilon}_{\mathrm{n}+1}^{\mathrm{vp}}$ and the viscoplastic strain $\dot{\varepsilon}_{\mathrm{n}+1}^{\mathrm{vp}}$ must be computed:

$$
f_{\mathrm{n}+1}^{\mathrm{g}}>0 \Rightarrow \Delta \gamma>0 \Rightarrow \varepsilon_{\mathrm{n}+1}^{\mathrm{vp}} \neq \varepsilon_{\mathrm{n}}^{\mathrm{vp}} \quad \text { and } \quad \sigma_{\mathrm{n}+1} \neq \sigma_{\mathrm{n}}
$$

where $\Delta \gamma=\int_{t_{\mathrm{n}}}^{t_{\mathrm{n}+1}} \gamma d t$. The definition of $\sigma_{\mathrm{n}+1}$ yields $\sigma_{\mathrm{n}+1}=\mathrm{E}\left(\varepsilon_{\mathrm{n}+1}-\varepsilon_{\mathrm{n}+1}^{\mathrm{vp}}\right)$ which may be written as $\sigma_{\mathrm{n}+1}=\mathrm{E}\left(\varepsilon_{\mathrm{n}+1}-\varepsilon_{\mathrm{n}}^{\mathrm{vp}}\right)-\mathrm{E}\left(\varepsilon_{\mathrm{n}+1}^{\mathrm{vp}}-\varepsilon_{\mathrm{n}}^{\mathrm{vp}}\right)$ thus $\sigma_{\mathrm{n}+1}=\sigma_{\mathrm{n}+1}^{\mathrm{g}}-\mathrm{E} \Delta \gamma$. Accordingly, the state of the system at $t_{\mathrm{n}+1}$ is fully described by the following set of equations:

$$
\begin{aligned}
& \sigma_{\mathrm{n}+1}=\sigma_{\mathrm{n}+1}^{\mathrm{g}}-\mathrm{E} \Delta \gamma \\
& \varepsilon_{\mathrm{n}+1}^{\nu p}=\varepsilon_{\mathrm{n}}^{\mathrm{vp}}+\Delta \gamma \\
& \alpha_{\mathrm{n}+1}=\alpha_{\mathrm{n}}+\Delta \gamma \\
& f_{\mathrm{n}+1}=\sigma_{\mathrm{n}+1}-\left(\sigma_{\mathrm{Y}}+\mathrm{K} \alpha_{\mathrm{n}+1}\right)
\end{aligned}
$$

where $\Delta \gamma$ only is unknown. Combining Eq. (12a) and (12d) yields $f_{\mathrm{n}+1}=\sigma_{\mathrm{n}+1}^{\mathrm{g}}-\mathrm{E} \Delta \gamma-$ $\left(\sigma_{\mathrm{Y}}+\mathrm{K} \alpha_{\mathrm{n}+1}\right)$ or $f_{\mathrm{n}+1}=\sigma_{\mathrm{n}+1}^{\mathrm{g}}-\mathrm{E} \Delta \gamma-\left(\sigma_{\mathrm{Y}}+\mathrm{K} \alpha_{\mathrm{n}}\right)-\mathrm{K}\left(\alpha_{\mathrm{n}+1}-\alpha_{\mathrm{n}}\right)$ which becomes:

$$
f_{\mathrm{n}+1}=f_{\mathrm{n}+1}^{\mathrm{g}}-\mathrm{E} \Delta \gamma-\mathrm{K}\left(\alpha_{\mathrm{n}+1}-\alpha_{\mathrm{n}}\right)
$$

as deduced from Eq. (9a). Also, it is to be noted that:

$$
\alpha_{\mathrm{n}+1}-\alpha_{\mathrm{n}}=[\alpha]_{t_{\mathrm{n}}}^{t_{\mathrm{n}+1}}=\int_{t_{\mathrm{n}}}^{t_{\mathrm{n}+1}} \dot{\alpha} d t=\int_{t_{\mathrm{n}}}^{t_{\mathrm{n}+1}} \gamma d t=\Delta \gamma
$$

and consequently Eq. (13) becomes $f_{\mathrm{n}+1}=f_{\mathrm{n}+1}^{\mathrm{g}}-\Delta \gamma(\mathrm{E}+\mathrm{K})$. Assumption (4) then provides $\eta \dot{\varepsilon}_{\mathrm{n}+1}^{\mathrm{vp}}=f_{\mathrm{n}+1}^{\mathrm{g}}-\Delta \gamma(\mathrm{E}+\mathrm{K})$ which is equivalent to:

$$
\eta \gamma_{\mathrm{n}+1}=f_{\mathrm{n}+1}^{\mathrm{g}}-\Delta \gamma(\mathrm{E}+\mathrm{K})
$$

Finally, by plugging Eq. (14) into Eq. (15) we obtain:

$$
\Delta \gamma=\frac{f_{\mathrm{n}+1}^{\mathrm{g}}+\gamma_{\mathrm{n}} \cdot \eta}{\frac{2}{h} \cdot \eta+\mathrm{E}+\mathrm{K}}
$$

and the solution to the system of equations given in Eq. (12) is now explicitly known.

The system is then fully described at the $(n+1)^{\text {th }}$ time step with respect to the previous and guessed states and time is updated. 


\begin{tabular}{cc}
\hline $\mathrm{E}$ & $90 \cdot 10^{9} \mathrm{~Pa}$ \\
$\mathrm{~K}$ & $15 \cdot 10^{9} \mathrm{~Pa}$ \\
$\eta$ & $5 \cdot 10^{4} \mathrm{~Pa} \mathrm{~s}$ \\
$\sigma_{\mathrm{Y}}$ & $1 \cdot 10^{7} \mathrm{~Pa}$ \\
\hline
\end{tabular}

Table 1: Parameters of interest for the sensitivity analysis

\section{Numerical simulations}

The viscoplastic constitutive law developed above involves four parameters: (1) the Young's modulus E, (2) the plastic modulus $K$, (3) the yield limit $\sigma_{Y}$ and (4) the viscoplastic coefficient $\eta$. It is now intended to calibrate these four parameters in order to address the relevance of the proposed model, the possibility of reliable abradable material/tool predictions and accurate blade/casing interaction simulations. Also, consideration is primarily given to the vibratory levels experienced by the tool since this information together with subsequent stress amplitudes is crucial for blade designers. A proper description of the induced abradable material removal is secondary. To this end, this section describes an interaction simulation carried out with the numerical parameters listed in Tab. 1 and the corresponding sensitivity analysis of the model is assessed.

\subsection{Interaction simulation}

The tool/abradable material interaction phenomenon occurs between times $t=t_{b}$ and $t=t_{e}$. During the interaction, attention is given to three quantities: (1) the contact forces $\left(\mathrm{F}_{i}\right)_{i=1, \ldots, 5}$ acting on each boundary node $\left(c_{i}\right)_{i=1, \ldots, 5}$ of the tool blade along the axial direction $\mathbf{z},(2)$ the displacements $\left(u_{x, i}\right)_{i=1, \ldots, 5}$ and $\left(u_{z, i}\right)_{i=1, \ldots, 5}$ in the $\mathbf{x}$ and $\mathbf{z}$ directions respectively, and (3) the wear profile exhibited by the abradable liner for each boundary node.

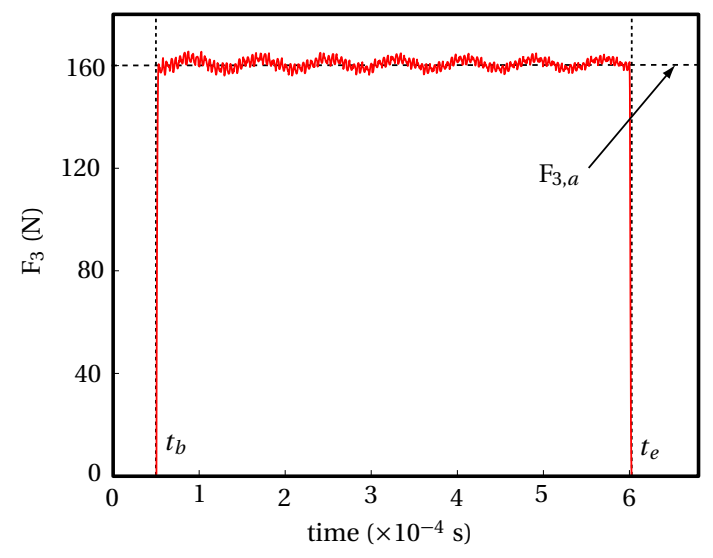

(a) First contact zone

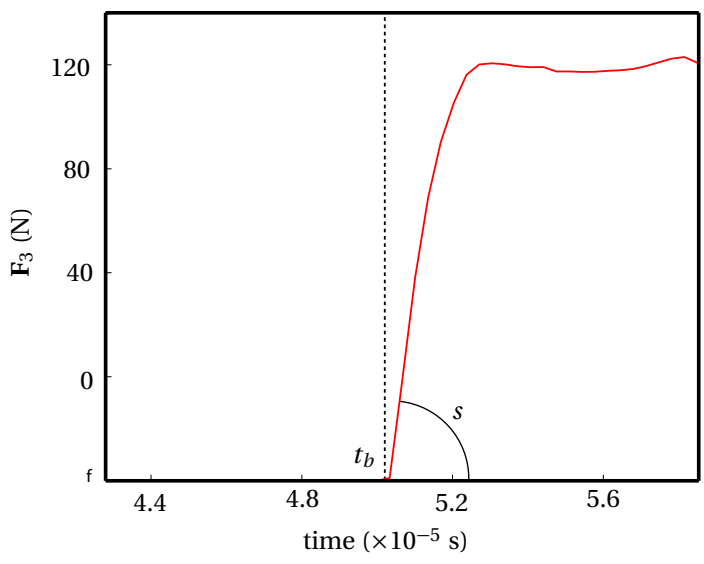

(b) Zoom

Figure 8: Contact force acting on node $c_{3} ;\|\mathbf{V}\|=200 \mathrm{~m} / \mathrm{s}$ and $p=0.2 \mathrm{~mm}$

For obvious symmetry considerations, displacements in the $\mathbf{y}$ direction are negligible compared to those in the $\mathbf{x}$ and $\mathbf{z}$ directions and are not plotted.

The sharpness $r$ depicted in Fig. 4 is essentially a numerical parameter. Although this radius may be seen as the characterization of the keenness of the cutting edge of the tool, it 
mostly bears on numerical convergence issues. An all-or-nothing penetration of the tool in the abradable at a specific time step should be discarded to preclude numerical instabilities. In this work, experimental observations [12] dictate the choice $r=25 \mu \mathrm{m}$. The first simulation is

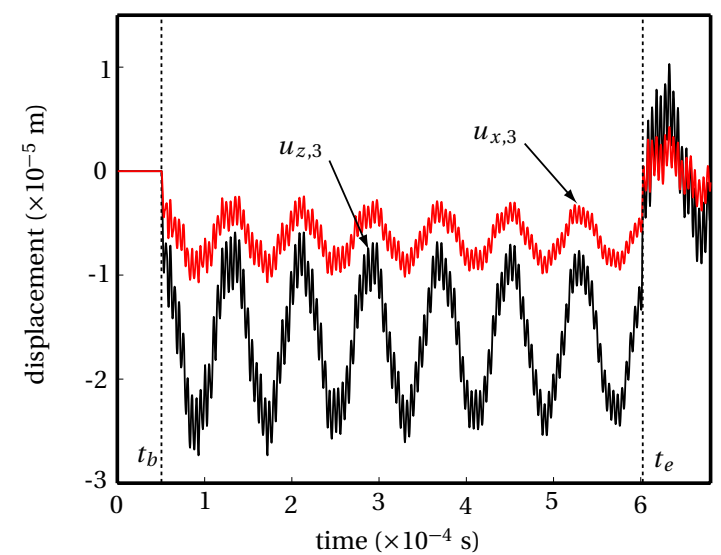

Figure 9: Displacements $u_{x, 3}$ and $u_{z, 3}$ of node $c_{3} ;\|\mathbf{V}\|=200 \mathrm{~m} / \mathrm{s}$ and $p=0.2 \mathrm{~mm}$

carried out with $\|\mathbf{V}\|=200 \mathrm{~m} / \mathrm{s}$ and $p=0.2 \mathrm{~mm}$. Displacements of node $c_{3}$ and corresponding contact forces are depicted in Figs. 9 and 8(a), respectively. Very similar results are observed on the other boundary nodes.

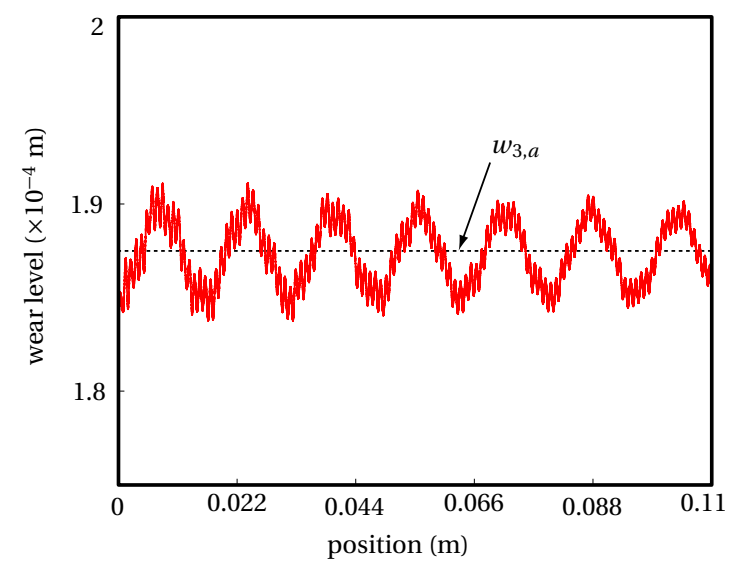

Figure 10: Wear profile after interaction; $\|\mathbf{V}\|=200 \mathrm{~m} / \mathrm{s}$ and $p=0.2 \mathrm{~mm}$

In Fig. 8(a), the contact force in the $\mathbf{z}$ direction is essentially constant during the interaction. An average value denoted by $\mathrm{F}_{3, a}{ }^{4}$ is computed over the time-range of interest $t \in\left[t_{b} ; t_{e}\right]$. The smoothing effect of the numerical profile detailed in Fig. 4 clearly arises in the zoomed illustration 8 (b) at the beginning of the interaction. The non-zero sharpness of the numerical profile allows for a non-infinite slope $s-$ the higher the sharpness, the smaller the slope - of the contact force at $t=t_{b}$ but has an unimportant impact on $\mathrm{F}_{3, a}$ which mostly depends on $\mathbf{V}$ and $p$. From here onward, the mean axial contact force exercised on the tool will be referred to as

${ }^{4}$ For a given contact node $i, \mathrm{~F}_{i, a}$ is the mean contact force of $\mathrm{F}_{i}$ defined in Eq. (2). 
$\|\mathbf{F}\|$ and defined by:

$$
\|\mathbf{F}\|=\sum_{k=1}^{5} \mathrm{~F}_{k, a}
$$

Finally, the final wear level on the abradable material resulting from the interaction is plotted in Fig. 10. The average value of the wear level - displayed as $w_{3, a}-$ is slightly smaller than the relative penetration $p: w_{3, a} \simeq 0.187 \mathrm{~mm}$ while $p=0.2 \mathrm{~mm}$. This is justified by the elastic contribution of the deformation of the abradable elements during interaction. Also, the amplitude of the worn lobes is in agreement with displacement $u_{x, 3}$ pictured in 9 .

\subsection{Sensitivity analysis of the model}

Results with parameters in Tab. 1 are plotted as solid line in Figs. 11(a), 11(b), 11(c), and 11(d). Dashed lines depict the variation of one of the aforementioned parameters only.

When the Young's modulus E tends to infinity, the axial force on the tool $\|\mathbf{F}\|$ becomes linearly dependent on the projectile speed. Smaller E generate lower interaction forces as shown in Fig. 11(a). When $\mathrm{E}$ is sufficiently large, plastic effects become negligible and the computation of the axial force acting on the tool solely involves the amount of removed abradable material: this quantity is proportional to the projectile speed. Changing the Young's modulus essentially affects the curvature of the graph ${ }^{5}$. Also, in Fig. 11(b), the computed axial contact force increases with $\eta$. When $\eta$ tends to zero, viscoplastic effects become negligible and the axial contact force becomes constant and independent of the projectile speed.

Increased plastic modulus and yield limit have similar effects as depicted in Fig 11(c) and Fig. 11(d). Sequentially increasing each of them yield a positive offset value of the axial contact force when the tool is motionless. However, an increase of the plastic modulus has more impact for high speed test cases while an increase of the yield limit impacts low speed simulations. High-speed tool motions are more sensitive to the plastic modulus while their low-speed counterparts are functions of the yield limit.

The last parameter of interest is the incursion depth $p$ of the tool in the abradable material. Its influence upon the targeted quantities is displayed in Fig. 11(e). As expected, the higher $p$, the higher the contact force on the blade. In addition, the contact force varies quite significantly for small alterations of $p$. A calibration procedure is then conducted to fit numerical results with experimental data supplied in [12]. Calibrated parameters are given in Tab. 2. It is worthy to note that the calibrated Young's modulus is significantly higher than the experimental value obtained for abradable material M601. It seems very likely that the modeling of

\begin{tabular}{ccc}
\hline & calibrated value & experimental (static) value [7] \\
\hline $\mathrm{E}$ & $60 \cdot 10^{9} \mathrm{~Pa}$ & $2.1 \pm 0.9 \cdot 10^{9} \mathrm{~Pa}$ \\
$\mathrm{~K}$ & $15 \cdot 10^{9} \mathrm{~Pa}$ & - \\
$\eta$ & $5 \cdot 10^{4} \mathrm{~Pa} \mathrm{~s}$ & - \\
$\sigma_{\mathrm{Y}}$ & $7 \cdot 10^{6} \mathrm{~Pa}$ & $6.9 \cdot 10^{6} \mathrm{~Pa}$ \\
\hline
\end{tabular}

Table 2: Numerical and experimental material properties of the abradable material

abradable material removal through the compression of one-dimensional abradable elements

\footnotetext{
${ }^{5}$ Depending on the Young's modulus, the model may predict a restoration of the liner depth after deformation instead of removal.
} 


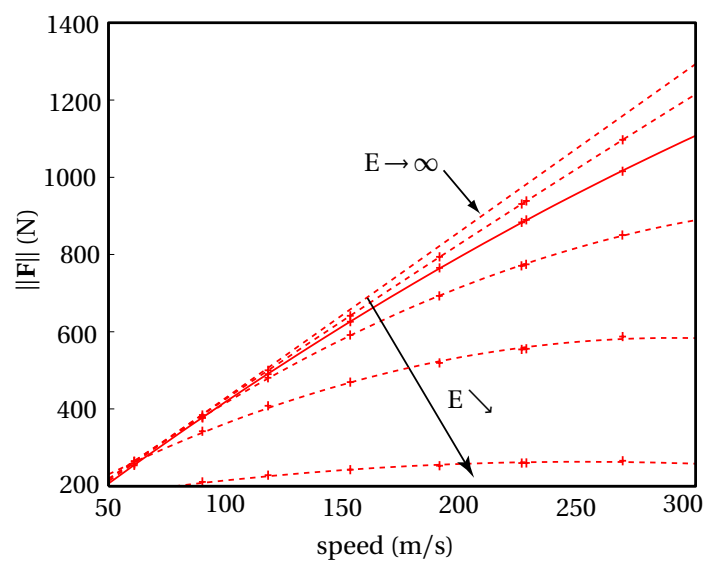

(a) to Young's modulus E

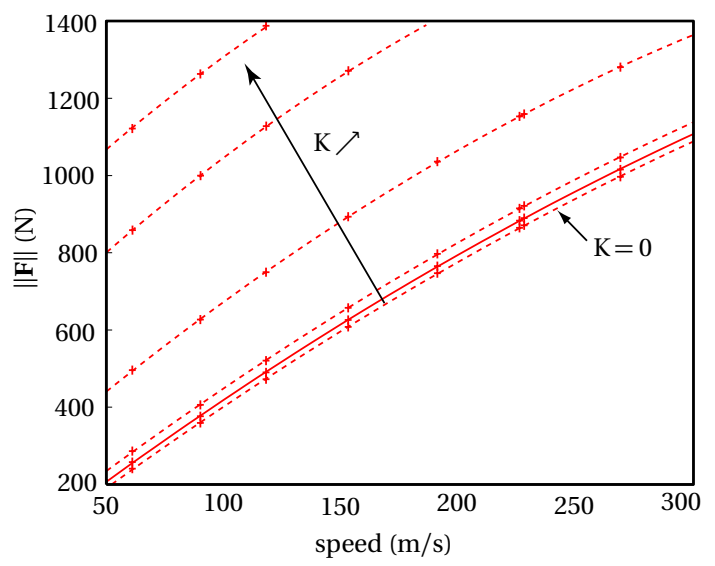

(c) to Plastic modulus K

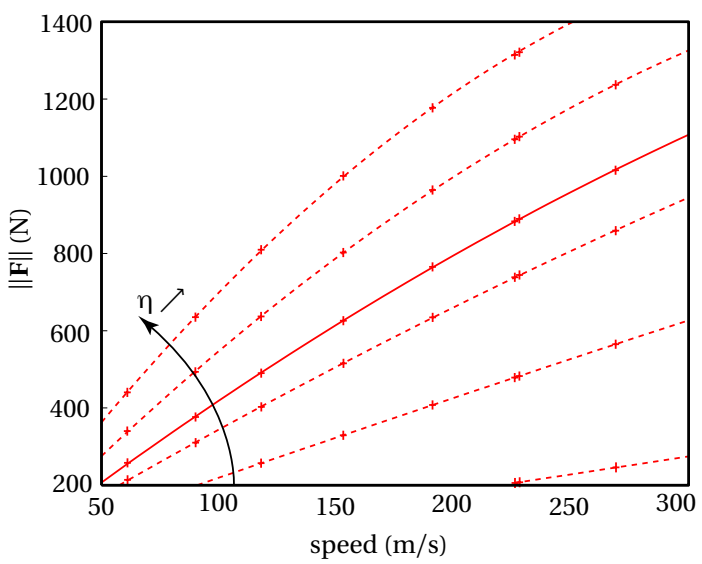

(b) to viscoplastic coefficient $\eta$

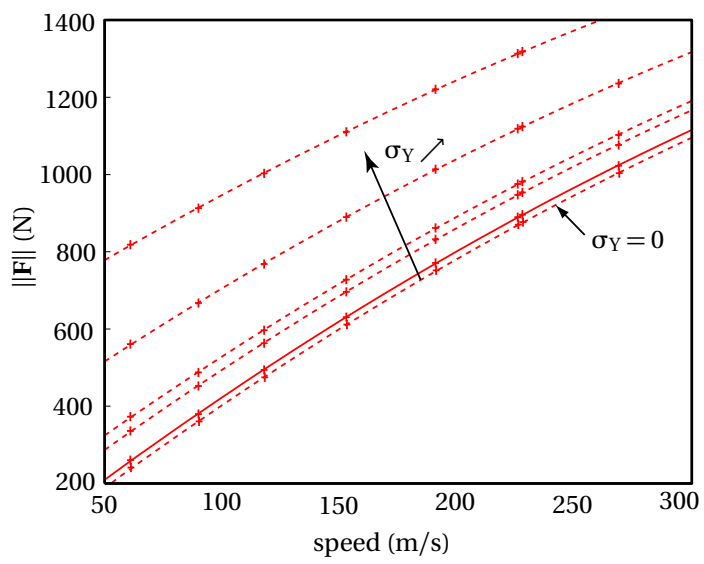

(d) to Yield limit $\sigma_{\mathrm{Y}}$

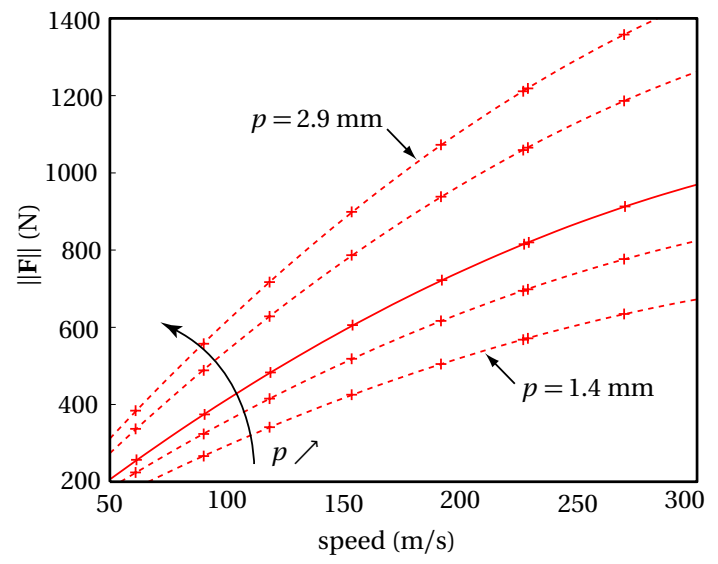

(e) to penetration in the abradable $p$

Figure 11: Sensitivity of the numerically predicted contact force

is responsible for this numerical over-evaluation of these parameters owing to the fact that many phenomena are ignored in the proposed viscoplastic constitutive law. 


\subsection{Comparison with experimental data}

Experimental data used in this section is extracted from [12]. The interaction speed reaches $300 \mathrm{~m} / \mathrm{s}$ and the penetration in the abradable is experimentally set to $p=0.2 \mathrm{~mm}$. Because of the wide interaction speed range covered from 50 to $300 \mathrm{~m} / \mathrm{s}$, this data set may be compared with an actual blade-tip/abradable coating interaction case since the linear speed of a lowpressure compressor blade tip is approximately $350 \mathrm{~m} / \mathrm{s}$.

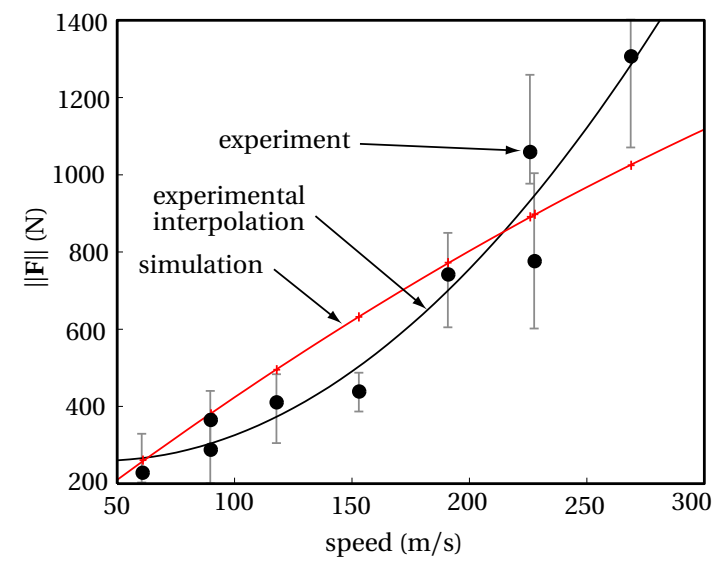

(a) $p=2 \cdot 10^{-4} \mathrm{~m}$ in numerical simulations

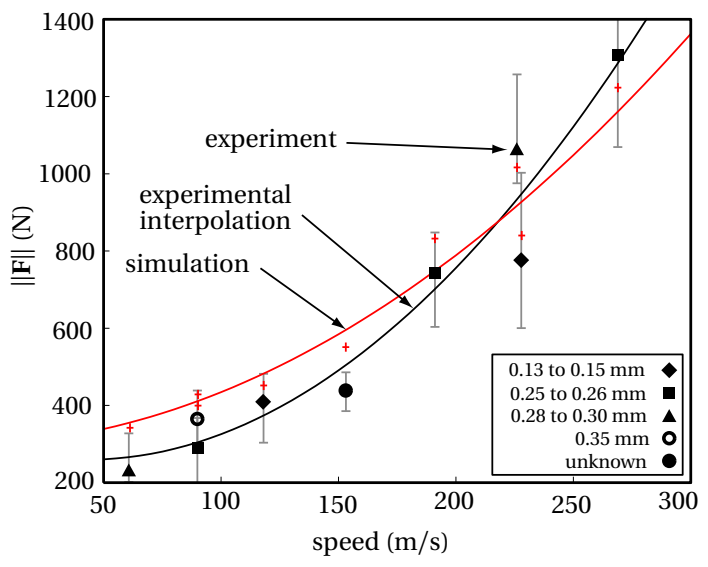

(b) With the variation of $p$

Figure 12: Experimental data [12] and numerical results. Uncertainty on experimental data is highlighted in gray

A meticulous measurement of the surface of the projectile has experimentally shown that the actual penetration of the tool inside the abradable material varies on average from $p=$ $0.14 \mathrm{~mm}$ to $p=0.29 \mathrm{~mm}$ as mentioned in section 3.1. Accordingly, numerical simulations are carried out with and without accounting for the variation of the penetration $p$ in order to assess the significance of this variation

Accouting or not for these geometrical alterations has the following effects:

- results when $p$ is kept constant are plotted beside experimental data points in Fig. 12(a) together with their respective second-degree polynomial interpolations. Experimental results in black in Fig. 12(a) show that the interaction force non-linearly increases with the tool speed. Numerical and experimental results match well over the interaction speed range but the curvature of both interpolations is opposed and large discrepancies are observed for high interaction speeds.

- when the variations of $p$ are accounted for, numerical and experimental results depicted in Fig. 12(b) match very well. The curvatures of both interpolations are also in accordance.

\subsection{Industrial context}

Modern turbomachinery designs feature clearance reduction between rotating and static components for improved energy efficiency but frequent blade-tip/casing contacts are expected [21, 10]. Subsequently to these contacts, a few critical interaction phenomena leading to blade failure were experimentally observed [22] and numerically simulated [11] using the plastic constitutive law. 
Considering the relatively small strain-rate ${ }^{6}$ in the abradable coating during blade-tip/casing contacts, $\dot{\varepsilon} \simeq 10 \mathrm{~s}^{-1}$, it was assumed in [10] that strain-rate dependence may be neglected during the interaction. However, since results in [12] are clearly sensitive to the abradable material strain-rate, the aim of this section is to assess the influence of viscoplasticity in the bladetip/casing interaction with the blade model described in [10] and used in [11]. The corresponding mechanical properties are given in Tab. 2 and the blade covers exactly fifty revolutions.

\subsubsection{Frequency domain analysis}

Simulations are carried out over the rotation frequency range of the blade: $f_{\Omega} \in[0.05 ; 0.5]$. A Fourier transform of the radial displacement of the contact node on the trailing edge is computed for each simulation and the corresponding full spectrum of the blade response over the considered rotational frequency range is constructed for each $\eta$.

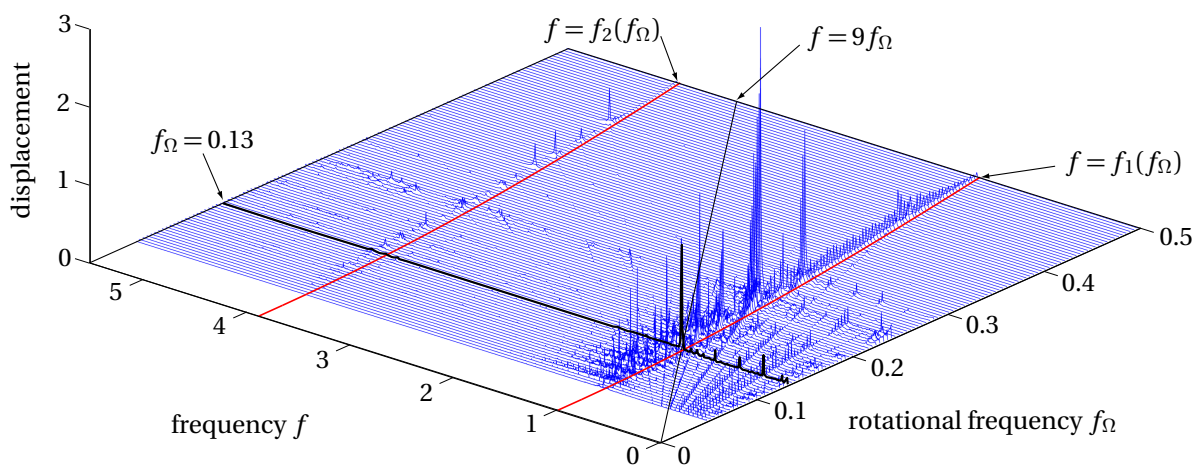

Figure 13: Blade response spectrum for $\eta=50,000$ Pa s

The blade response spectrum is plotted for $\eta=50,000$ Pa s in Fig. 13. Only minor differences in peak amplitude are noticeable with the same spectrum for $\eta=0$ Pa s which is not plotted here for the sake of brevity. This corroborates the assumption that the viscoplasticity in blade-tip/abradable coating interaction is negligible.

\subsubsection{Wear levels}

For each rotational velocity, the final wear profile of the abradable material is retrieved. Through a contiguous organization of these profiles, a wear map is constructed and displays useful information about possible critical velocities for which blade incursions in the abradable liner may be large. As such, these maps also emphasize the privileged contact areas on the casing.

Trailing edge blade wear map is plotted for $\eta=50,000$ Pa s in Fig. 14. No substantial difference does emerge between this wear map and the one obtained for $\eta=0$ Pa s eventhough wear levels are slightly higher for $\eta=50,000$ Pa s. This may be surprising since the yield limit depends on $\eta$ : the higher it is, the higher the stress in the abradable element should be to reach plastic residual deformation. However, previous results [23] underlined that abradable materials with a higher Young's modulus - for which a higher stress is required in the element to reach plastic deformation - could lead to higher levels of vibration and subsequent higher wear levels.

\footnotetext{
${ }^{6}$ The value of the strain-rate given in this paper comes from industrial observations.
} 


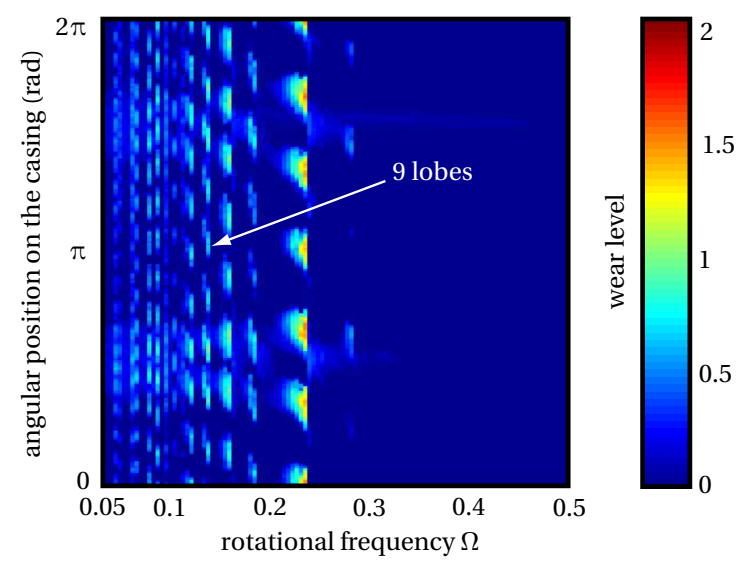

Figure 14: Final abradable profile maps after fifty blade revolutions; $\eta=50,000 \mathrm{~Pa} \mathrm{~s}$

In addition to a slightly increased wear, new interaction profiles may be observed such as a 9-lobe wear profile shown in Fig. 14 that emanates at $f_{\Omega}=0.13$. However, theses new interaction profiles feature relatively low vibration amplitudes and thus do not significantly impact the dynamics of the blade.

These results support the fact that viscoplasticity negligibly alters blade-tip/abradable coating interactions. Accordingly, the law detailed in [10] may be used without significant loss of accuracy.

\section{Conclusion}

Based on the numerical strategy proposed in [10], a four parameter viscoplastic constitutive law is developed for the numerical approximations of motionless tool/projected abradable material patch interaction experiments. The associated experimental set-up comprises a gas gun that can throw a projectile guided in a launch tube to up to $300 \mathrm{~m} / \mathrm{s}$. The interaction occurs within a vacuum chamber where a tool made of titanium cuts the layer of abradable coating sprayed on the projectile. The material parameters of the viscoplastic constitutive law are adjusted to experimental measurements and it is shown that numerical and experimental results — obtained from [12] — match well over the considered range of interaction velocities. It is also underlined that when the undesired experimental incertitude of the incursion depth of the tool within the abradable coating is accounted for, both the amplitude of the axial contact force and its dependence to the projectile speed are accurately reproduced.

For a given incursion depth, the numerical model predicts a concave distribution of the data points in the force-interaction speed plane. Also, consistently with previous studies [14], the good agreement between numerical and experimental results corroborate the fact that thermal effects may be negligible - in the specific case of very short tool/abradable interaction durations - since they are ignored in the introduced numerical simulations.

In order to assess the sensitivity of the blade-tip/abradable coating interactions to the viscoplastic parameters, a test case allows for a comparison to the original plastic constitutive law. It is confirmed that, because of the relatively small strain-rates encountered during the investigated interactions, the viscoplastic coefficient plays a negligible role in the phenomenon. However, extreme interaction scenarios may require the convenient addition of viscoplasticity 
for reliable numerical predictions.

\section{Acknowledgement}

Thanks go to Snecma for its technical and financial support. This work takes place in the framework of the MAIA mechanical research and technology program sponsored by CNRS, ONERA and SAFRAN Group.

\section{References}

[1] Schmiechen, P., 1997. "Travelling wave speed coincidence”. Ph.d. thesis, College of Science, Technology and Medicine, London, UK. ISBN-13:462 978-3183260119. 2

[2] Padova, C., Barton, J., Dunn, M., Manwaring, S., Young, G., Adams, M., and Adams, M., 2005. "Development of an experimental capability to produce controlled blade tip/shroud rubs at engine speed". Journal of Turbomachinery, 127, pp. 726-735. 2

[3] Groll, G. V., and J., E. D., 2001. "The harmonic balance method with arc-length continuation in rotor/stator contact problems". Journal of Sound and Vibration, 241, pp. 223-233. DOI:10.1006/jsvi.2000.3298. 2

[4] Legrand, M., Pierre, C., Cartraud, P., and Lombard, J.-P., 2009. “Two-dimensional modeling of an aircraft engine structural bladed disk-casing modal interaction”. Journal of Sound and Vibration, 319(1-2), pp. 366 - 391. DOI:10.1016/j.jsv.2008.06.019 also available on HAL:hal-00328186. 2, 7

[5] Batailly, A., Legrand, M., Cartraud, P., and Pierre, C., 2010. "Assessment of reduced models for the detection of modal interaction through rotor stator contacts". Journal of Sound and Vibration, 329, pp. 5546-5562. DOI:10.1016/j.jsv.2010.07.018 also available on HAL:hal-00524762. 2, 6

[6] Yi, M., J., H., Huang, B., and Zhou, H., 1999. "Friction and wear behaviour and abradability of abradable seal coating”. Wear, 231, pp. 47-53. 2, 3

[7] Ma, X., and Matthews, A., 2009. "Evaluation of abradable seal coating mechanical properties". Wear, 267, pp. 1501-1510. DOI:10.1016/j.wear.2009.03.044. 2, 3, 9, 13

[8] Peyraut, F., Seichepine, J. L., Coddet, C., and Hertter, M., 2008. "Finite element modeling of abradable materials - identification of plastic parameters and issues on minimum hardness against coating's thickness". International Journal for Simulation and Multidisciplinary Design Optimization, 2, pp. 209-215. DOI:10.1051/ijsmdo:2008028. 2

[9] Bounazef, M., Guessasma, S., and B., A. S., 2004. "The wear, deterioration and transformation phenomena of abradable coating BN-SiAl-bounding organic element, caused by the friction between the blades and the turbine casing". materials letters, $\mathbf{5 8}$, pp. 3375-3380. DOI:10.1016/j.matlet.2004.02.049. 2

[10] Legrand, M., Batailly, A., and Pierre, C., 2011. "Numerical investigation of abradable coating removal in aircraft engines through plastic constitutive law". Journal of 
Computational and Nonlinear Dynamics, 7. DOI:10.1115/1.4004951 and available on HAL:hal-00627526. 2, 6, 7, 8, 15, 17

[11] Batailly, A., Legrand, M., Millecamps, A., and Garcin, F., 2012. "Numerical-experimental comparison in the simulation of rotor/stator interaction through blade-tip/abradable coating contact”. Journal of Engineering for Gas Turbines and Power, 134.

DOI:10.1115/1.4006446 also available on HAL:hal-00746632. 2, 15

[12] Cuny, M., 2012. "Contribution à la caractérisation locale des couples de matériaux mis en jeu lors du contact rotor/stator dans une turbomachine". PhD thesis, Université de Lorraine, France. 3, 4, 5, 7, 8, 11, 13, 15, 17

[13] Ma, X., and Matthews, A., 2007. "Investigation of abradable seal coating performance using scratch testing”. Surface \& coatings technology, 202, pp. 1214-1220.

DOI:10.1016/j.surfcoat.2007.07.076. 3

[14] Sutter, G., Philippon, S., and Garcin, F., 2006. "Dynamic analysis of the interaction between an abradable material and a titanium alloy". Wear, 261, pp. 686-692. DOI:10.1016/j.wear.2006.01.030. 5, 7, 17

[15] Craig, R., and Bampton, C., 1968. "Coupling of substructures for dynamics analyses". AIAA Journal, 6(7), pp. 1313 - 1319. 6

[16] Batailly, A., 2008. "Simulation de l'interaction rotor/stator pour des turbomachines aéronautiques en configuration non-accidentelle”. Thèse de doctorat, École Centrale de Nantes, Nantes, France. available on TEL:tel-00364945. 6

[17] Zubov, V. I., Stepanov, G. V., and V., S. A., 2003. "Effect of the strain rate on the yield strength of steels of different strength". Strength of Materials, 35, pp. 514-520. 8, 9

[18] Simo, J. C., and Hughes, T. J. R., 1998. Computational inelasticity. Springer-Verlag. 8

[19] Legrand, M., and Pierre, C., 2009. "Numerical investigation of abradable coating wear through plastic constitutive law: Application to aircraft engines". In Proceedings of the ASME IDETC/CIE - DETC2009-87669. available on HAL:hal-00413728. 8

[20] Rosen, R. S., Paddon, S. P., and Kassner, M. E., 1999. “The variation of the yield stress of ti alloys with strain rate at high temperatures". Journal of Materials Engineering and Performance, 8, pp. 361-367. 9

[21] Williams, R. J., 2011. "Simulation of blade casing interaction phenomena in gas turbines resulting from heavy tip rubs using an implicit time marching method". In Proceedings of the ASME Turbo Expo 2011 - GT2011-45495. 15

[22] Millecamps, A., Brunel, J. F., Dufrénoy, P., Garcin, F., and Nucci, M., 2009. "Influence of thermal effects during blade-casing contact experiments". In Proceedings of the ASME IDETC/CIE - DETC2009-86842. 15

[23] Batailly, A., Legrand, M., and Pierre, C., 2008. "Influence of abradable coating wear mechanical properties on rotor stator interaction". In Proceedings of the ASME Turbo Expo 2011 - GT2011-45189. available on HAL:hal-00616524_v1. 16 